\title{
Breizacanthus aznari sp. n. (Acanthocephala: Arhythmacanthidae) from the banded cusk-eel Raneya brasiliensis (Ophidiiformes: Ophidiidae) from the Patagonian coast in Argentina
}

\author{
Jesús Servando Hernández-Orts ${ }^{1}$, Gema Alama-Bermejo ${ }^{2}$, Enrique Alberto Crespo ${ }^{3}$, Néstor Aníbal García ${ }^{3}$, \\ Juan Antonio Raga ${ }^{1}$ and Francisco Esteban Montero ${ }^{1}$
}

\author{
${ }^{1}$ Cavanilles Institute of Biodiversity and Evolutionary Biology, Science Park, University of Valencia, C/ Catedrático José Beltrán 2 , \\ 46980, Paterna, Valencia, Spain; \\ ${ }^{2}$ Laboratory of Fish Protistology, Institute of Parasitology, Biology Centre, ASCR, Branišovská 31, 370 05, České Budějovice, \\ Czech Republic; \\ ${ }^{3}$ Marine Mammal Laboratory, National Patagonic Center, CONICET and University of Patagonia, Boulevard Brown 2915 (9120), \\ Puerto Madryn, Chubut, Argentina
}

\begin{abstract}
Breizacanthus aznari sp. n. is described from the banded cusk-eel Raneya brasiliensis (Kaup) (Ophidiiformes: Ophidiidae) from the Patagonian coast in Argentina. Breizacanthus Golvan, 1969 is currently composed of five species (including the new species) and is characterised by the absence of trunk spines, a short cylindrical proboscis with two types of hooks and lemnisci longer than the proboscis receptacle. Breizacanthus aznari is clearly distinguished from B. chabaudi Golvan, 1969 by having 12 longitudinal rows of hooks on the proboscis, instead of 16-18. The new species resembles B. golvani Gaevskaya et Shukhgalter, 1984, B. irenae Golvan, 1969, and B. ligur Paggi, Orecchia et Della Seta, 1975, all possessing 12 longitudinal rows of hooks. However, $B$. aznari differs from $B$. golvani in having 4-5 large hooks per row (vs. 8-9) and larger eggs. The new species can be distinguished from $B$. irenae by the shorter body size of females, the different range of numbers of large hooks of males (4-5 and 5-6, respectively), the smaller maximum number of small hooks of females ( 3 and 4, respectively), and the shorter lemnisci. Breizacanthus aznari differs from $B$. ligur by the smaller body length of females, the smaller maximum body length of males, the different range of numbers of large hooks of males (4-5 and 5-6, respectively), and smaller lemnisci. This is the first record of a species of Breizacanthus from fishes of the order Ophidiiformes and from the Southern Hemisphere. Comparative data on species of Euzetacanthus Golvan et Houlin, 1964 and Breizacanthus are also provided.
\end{abstract}

Keywords: spiny-headed worms, Palaeacanthocephala, Euzetacanthus, taxonomy, marine fish, southwestern Atlantic, Patagonia

The family Arhythmacanthidae Yamaguti, 1935 (Acanthocephala: Palaeacanthocephala) is currently composed of seven genera: Acanthocephaloides Meyer, 1932, Breizacanthus Golvan, 1969, Euzetacanthus Golvan et Houin, 1964, Heterosentis Van Cleave, 1931, Hypoechinorhynchus Yamaguti, 1939, Paracanthocephaloides Golvan, 1969, and Spiracanthus Muñoz et George-Nascimento, 2002 (see Pichelin and Cribb 1999, Muñoz and George-Nascimento 2002). All these genera are parasites of teleosts and are characterized by possessing six cement glands and by the abrupt transition on the proboscis from small basal hooks (with roots) or spines (without roots) to large, more apical hooks (Golvan 1969, Pichelin and Cribb 1999, Lanfranchi and Timi 2011).

During a survey of intestinal parasites of the banded cusk-eel Raneya brasiliensis (Kaup) (Ophidiiformes:
Ophidiidae) from the Patagonian coast in Argentina, several specimens of an arhythmacanthid acanthocephalan were collected. After a morphological and morphometric analyses, these worms appeared to be a new species of Breizacanthus that are described herein.

\section{MATERIALS AND METHODS}

\section{Sample collection}

The fish were caught by commercial bottom trawling vessels along the Argentine Patagonian shelf. Sixteen specimens of Raneya brasiliensis $19.8-23.3 \mathrm{~cm}$ total length (mean \pm standard deviation $=21.2 \mathrm{~cm} \pm 1.4 \mathrm{~cm}$ ) were collected in northern Patagonia $\left(42^{\circ} 45^{\prime}-42^{\circ} 59^{\prime} \mathrm{S}, 61^{\circ} 09^{\prime}-62^{\circ} 58^{\prime} \mathrm{W}\right.$, November 2007$)$. Fish were frozen in plastic bags at $-20^{\circ} \mathrm{C}$ for later examination. After thawing, each fish was dissected and the intestine was examined using a stereomicroscope (up to $40 \times$ ). Acanthocephalan specimens were washed in saline and fixed in $70 \%$ ethanol. 


\section{Morphological description}

For examination and measurements, worms were punctured with a fine needle and stained with eosin yellowish $(\mathrm{n}=3$; 4-5 min), Mayer's hematoxylin $(\mathrm{n}=2 ; 3 \mathrm{~min})$, or both stains $(\mathrm{n}=15)$, washed in distilled water for $1 \mathrm{~min}$ after each staining, dehydrated in ethanol, cleared in methyl salicylate and mounted in Canada balsam. Measurements, taken from drawings made with the aid of a drawing tube, are in micrometres unless otherwise stated and are presented as the mean followed by the standard deviation, with the range and number of structures measured in parentheses. Measurements of eggs were made from fully developed ones drawn in situ through the body wall of female worms.

Two specimens (one male and one female) were also studied with scanning electron microscopy (SEM). They were dehydrated through an ethanol series, critical point dried and coated with a gold-palladium alloy to a thickness of $250 \mathrm{~nm}$. Specimens were examined with a Hitachi $4100 \mathrm{FE}$ scanning electron microscope, operating at $20 \mathrm{kV}$, from the Central Service for the Support to Experimental Research (SCSIE) of the University of Valencia. Ecological terms follow Bush et al. (1997).

Specimens from the type series are deposited in the Natural History Museum (NHMUK), London, United Kingdom; the United States National Parasite Collection (USNPC), Beltsville, Maryland, United States; and the Helminthological Collection of the Institute of Parasitology (IPCAS), Biology Centre ASCR, České Budějovice, Czech Republic.

\section{RESULTS}

\section{Breizacanthus aznari sp. $\mathrm{n}$.}

Figs. 1-15

General: Arhythmacanthidae, with characters of Breizacanthus Golvan, 1969. Sexual dimorphism present, females larger than males (Figs. 1, 2, 10). Proboscis short and cylindrical (Figs. 1, 3, 11), armed with 12 longitudinal rows of hooks. Males with 6-7 hooks per row; each row with 4-5 large rooted hooks, and 2-3 small basal hooks with rudimentary roots (Figs. 3, 5, 11). Females with 7-8 hooks per row; each row with five large rooted hooks, and 2-3 small basal hooks with rudimentary roots (Figs. 4, 14). Neck present, unarmed (Figs. 2, 10), with a single pair of sensory pits (Figs. 11, 12). Trunk cylindrical to fusiform, thick-walled, completely unarmed (Figs. 1, 2, 6, 10, 13), slightly dilated in anterior end (Fig. 13). Proboscis receptacle double-walled (Fig. 6), $1.66 \pm 0.38$ $(1.19-2.16, \mathrm{n}=7)$ times longer than proboscis in males, and $1.71 \pm 0.35(1.33-2.20, \mathrm{n}=6)$ times longer in females, with ellipsoidal cephalic ganglion at its posterior end (Figs. 1, 2, 6). Lemnisci digitiform, longer than proboscis receptacle when fully extended (Figs. 1, 6). Left lemniscus with one elongated giant nucleus; right lemniscus with two giant nuclei (Fig. 6). Gonopore subterminal in both sexes. Genital spines absent (Figs. 7, 8, 15).

Male (based on 11 mounted specimens and one for $\mathrm{SEM}): 5.2 \pm 0.5 \mathrm{~mm}(4.7-6.0 \mathrm{~mm}, \mathrm{n}=6)$ long. Trunk elongated, slightly fusiform (Fig. 1), $4.6 \pm 0.7 \mathrm{~mm}(3.4-$ $5.5 \mathrm{~mm}, \mathrm{n}=10)$ long by $511 \pm 185(333-684, \mathrm{n}=10)$ wide. Proboscis $361 \pm 101(258-560, \mathrm{n}=10)$ long by
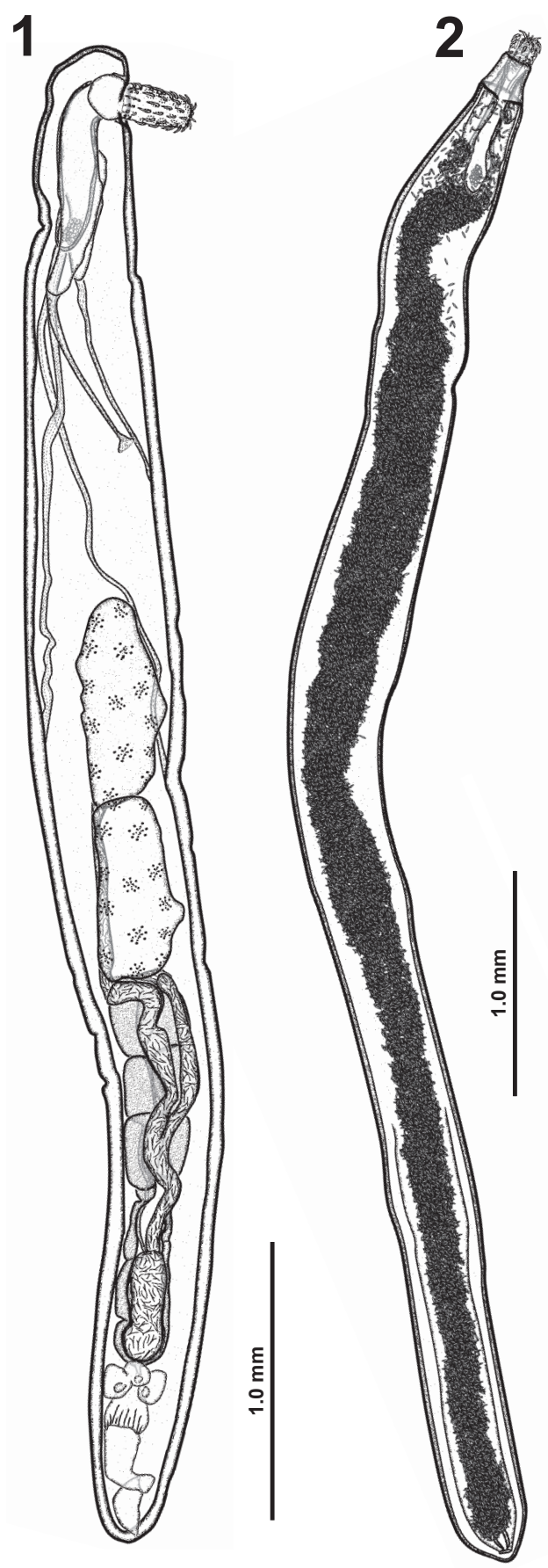

Figs. 1, 2. Breizacanthus aznari sp. n. from Raneya brasiliensis. 1. Male, whole mount (holotype) lateral view. 2. Female, whole mount (allotype), lateral view.

$173 \pm 52(124-259, \mathrm{n}=10)$ wide. Measurements of hooks are presented in Table 1 . Neck $138 \pm 21(107-168, \mathrm{n}=8)$ long by $179 \pm 28(143-216, \mathrm{n}=9)$ wide. Proboscis receptacle $536 \pm 34(466-586, \mathrm{n}=9)$ long by $114 \pm 15(95-$ $134, \mathrm{n}=9)$ wide. Lemnisci $634 \pm 38(578-691, \mathrm{n}=7)$ long. Proboscis receptacle/lemnisci length ratio $1: 0.8$ (0.8-0.9). Reproductive system occupying approximately $70 \% \pm 7(58-77 \%, \mathrm{n}=8)$ of trunk length (Fig. 1). Tes- 

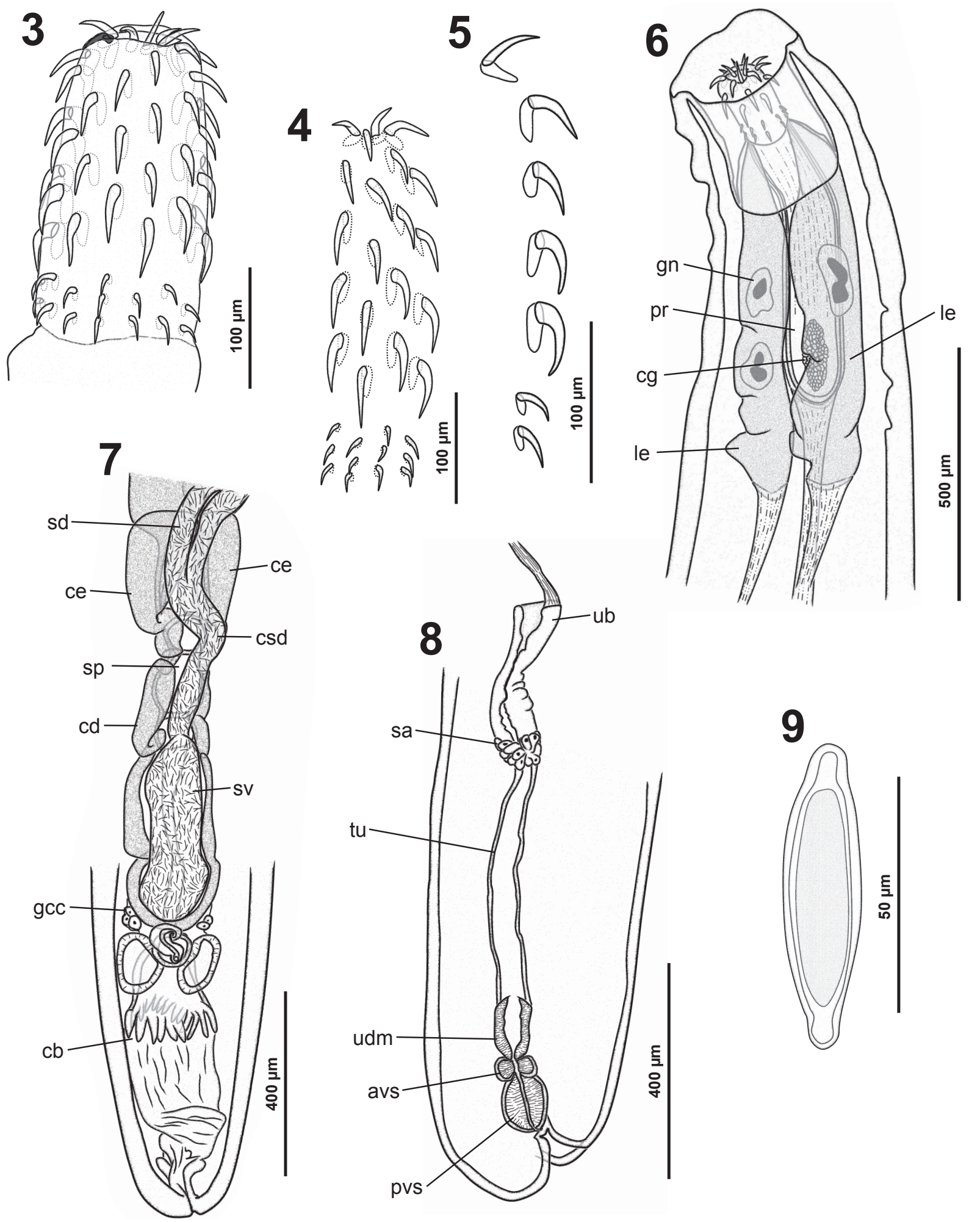

Figs. 3-9. Breizacanthus aznari sp. n. from Raneya brasiliensis. 3. Male proboscis armature (holotype), lateral view. Missing large sub-apical hook have been reconstructed with a black shadowed area. 4. Rows of hooks of female proboscis (paratype), ventral view; 5 - Male row of hooks (holotype), lateral view. 6. Female anterior body end, with detail of the proboscis receptacle and lemnisci (paratype), ventral view. 7. Detail of male genitalia (holotype), lateral view. 8. Female reproductive system (paratype), lateral view. 9. Immature egg (acanthor not illustrated). Abbreviations: avs - anterior vaginal sphincter; cb - copulatory bursa; cd - cement duct; ce - cement gland; cg - cephalic ganglion; csd - common sperm duct; gcc - glandular cellular cluster; gn - giant nucleus; le - lemniscus; $\mathrm{pr}$ - proboscis receptacle; pvs - posterior vaginal sphincter; sa - selector apparatus; sd - sperm duct; sp - Säeftingen's pouch; sv - seminal vesicle; tu - tubular uterus; ub - uterine bell; udm - uterus distal muscular region. 
Table 1. Morphometric data on the proboscis hooks of Breizacanthus aznari sp. n. from the banded cusk-eel Raneya brasiliensis from Patagonia, Argentina. Measurements in micrometres.

\begin{tabular}{lccccccc}
\hline & \multicolumn{4}{c}{ Male } & & \multicolumn{2}{c}{ Female } \\
\cline { 2 - 5 } \cline { 7 - 8 } & $\mathrm{n}$ & Blade & Root & & $\mathrm{n}$ & Blade & Root \\
\hline Apical & 3 & $38 \pm 2(36-40)$ & $26 \pm 1(25-26)$ & & 1 & 42 & 23 \\
Subapical I & 10 & $41 \pm 3(37-47)$ & $26 \pm 3(21-31)$ & & 2 & $37(33-40)$ & $25(23-27)$ \\
Subapical II & 8 & $45 \pm 5(36-50)$ & $27 \pm 10(23-31)$ & & 4 & $43 \pm 3(39-46)$ & $28 \pm 1(27-28)$ \\
Subapical III & 16 & $45 \pm 5(34-52)$ & $29 \pm 10(23-35)$ & & 9 & $45 \pm 4(39-52)$ & $28 \pm 4(23-34)$ \\
Subapical IV & 10 & $48 \pm 4(39-52)$ & $29 \pm 9(25-33)$ & & 30 & $49 \pm 4(40-54)$ & $30 \pm 4(23-42)$ \\
Basal I & 8 & $24 \pm 3(18-27)$ & $12 \pm 2(9-15)$ & & 10 & $20 \pm 3(15-23)$ & $8 \pm 3(6-10)$ \\
Basal II & 8 & $22 \pm 4(18-30)$ & $12 \pm 2(9-15)$ & & 10 & $21 \pm 2(17-23)$ & $10 \pm 5(8-14)$ \\
Basal III & 2 & $22(18-25)$ & $10(9-11)$ & & 3 & $24 \pm 4(21-29)$ & $10 \pm 5(8-15)$ \\
\hline
\end{tabular}

tes two, subellipsoidal, in tandem (Fig. 1). Anterior testis $621 \pm 174(368-926, \mathrm{n}=10)$ long by $261 \pm 51(168-358$, $\mathrm{n}=10)$ wide. Posterior testis $604 \pm 145(442-889, \mathrm{n}=10)$ long by $265 \pm 68(189-432, \mathrm{n}=10)$ wide. Cement glands six (Fig. 1), $280 \pm 89(155-466, \mathrm{n}=24)$ long by $149 \pm 41$ $(112-250, \mathrm{n}=25)$ wide, in three tandem pairs. Sperm ducts joining into common sperm duct at approximately level of distal pair of cement glands (Figs. 1, 7). Common sperm duct joining posteriorly to seminal vesicle (Figs. 1, 7). Seminal vesicle $340 \pm 121(167-547, \mathrm{n}=9)$ long, slightly constricted at mid-level (Fig. 7). Säefftingen's pouch dorsal to common sperm duct and seminal vesicle (Fig. 7), $379 \pm 70(297-526, \mathrm{n}=9)$ long. Cement ducts join with common sperm duct and Säeftingen's pouch anterior to copulatory bursa. Glandular cellular cluster observed at posterior junction of cement ducts, common sperm duct and Säeftingen's pouch (Fig. 7). Copulatory bursa with digital rays or papillae (Fig. 7), in all specimens inverted.

Female (based on 13 gravid mounted specimens and one for SEM): $6.9 \pm 1.2 \mathrm{~mm}(5.2-8.4 \mathrm{~mm}, \mathrm{n}=6)$ long. Trunk elongated, slightly fusiform (Fig. 2), $6.8 \pm 1.1 \mathrm{~mm}$ (4.9-8.3 mm, $\mathrm{n}=12)$ long by $517 \pm 58 \quad(421-611$, $\mathrm{n}=12)$ wide. Proboscis $323 \pm 36(272-375, \mathrm{n}=9)$ long by $122 \pm 27(96-184, \mathrm{n}=10)$ wide. Measurements of hooks in Table 1 . Neck $143 \pm 29(94-181, \mathrm{n}=7)$ long by $224 \pm 76(129-353, \mathrm{n}=7)$ wide. Proboscis receptacle $536 \pm 109(414-724, \mathrm{n}=10)$ long by $98 \pm 15(78-129$, $\mathrm{n}=10)$ wide. Lemnisci $666 \pm 142 \quad(466-905, \mathrm{n}=8)$ long. Proboscis receptacle/lemnisci length ratio $1: 0.8$ (0.7-0.9). Reproductive system $1123 \pm 165$ (985-1379, $\mathrm{n}=5$ ) long (Fig. 8), post-equatorial, occupying 17\% \pm 1 $(16-18 \%, \mathrm{n}=5)$ of trunk length. Uterine bell $331 \pm 92$ $(259-483, \mathrm{n}=7)$ long; selector apparatus present; tubular uterus $546 \pm 138(328-707, \mathrm{n}=7)$ long; uterus distal muscular region, $117 \pm 13(93-129, \mathrm{n}=7)$ long; anterior vaginal sphincter $56 \pm 19(36-86, \mathrm{n}=7)$ long; posterior vaginal sphincter $75 \pm 22(52-116, \mathrm{n}=6)$ long. Mature eggs, containing a fully developed acanthor, fusiform (Fig. 9), $63 \pm 5(53-73, \mathrm{n}=40)$ long by $14 \pm 1(11-17$, $\mathrm{n}=40$ ) wide.

Type host: banded cusk-eel, Raneya brasiliensis (Kaup) (Ophidiiformes: Ophidiidae).
Type 1ocality: Chubut, Argentina $\left(42^{\circ} 45^{\prime}-42^{\circ} 59^{\prime} \mathrm{S}\right.$, $61^{\circ} 09^{\prime}-62^{\circ} 58^{\prime} \mathrm{W}$ ).

Site in host: Intestine.

Type specimens: Holotype, male whole mount (NHMUK 2012.7.24.1); allotype, female whole mount (NHMUK 2012.7.24.2); paratypes, whole mounts of two males and two females (NHMUK 2012.7.24. 3-6); paratypes, whole mounts of two males and two females (USNPC 105889, 105890); and paratypes, whole mounts of two males and two females (IPCAS A-84).

Infection parameters: Prevalence $25 \%(n=16)$; abundance $=3.6$; mean intensity $=14.5$; intensity $=1-35$ acanthocephalans per fish.

Etymology: The new species is named for Dr. Francisco Javier Aznar of the University of Valencia in recognition of his contribution to the knowledge of the acanthocephalans.

Remarks: According to the genus diagnosis in Golvan (1969) and Pichelin and Cribb (1999), the acanthocephalans collected in the present study are assigned to the genus Breizacanthus, based on the absence of trunk spines, short cylindrical proboscis with two types of hooks and lemnisci longer than the proboscis receptacle. To date, four species are recognized in this genus: B. chabaudi Golvan, 1969; B. irenae Golvan, 1969; B. ligur Paggi, Orecchia et Della Seta, 1975; and B. golvani Gaevskaya et Shukhgalter, 1984 (Golvan 1969, Paggi et al. 1975, Gaevskaya and Shukhgalter 1984). Taxonomic data for each species within the genus Breizacanthus are presented in Table 2.

Breizacanthus aznari sp. n. differs from B. chabaudi by having a smaller body size (5.2-8.4 $\mathrm{mm}$ vs. 15.0$20.0 \mathrm{~mm}$ in females and 4.7-6.0 $\mathrm{mm} \mathrm{vs.} \mathrm{9-11} \mathrm{mm}$ in males), a proboscis with 12 longitudinal rows, instead of 16-18, and shorter lemnisci (466-905 $\mu \mathrm{m}$ vs. 2.1-2.2 mm in females and 534-691 $\mu \mathrm{m} v s .1 .8-2.4 \mathrm{~mm}$ in males).

Considering the number of longitudinal rows of hooks on the proboscis, the new species mostly closely resembles the other three species of the genus, each with 12 longitudinal rows. However, in contrast to the new species, B. golvani possesses 8-9 large hooks instead of 4-5 large hooks in each longitudinal row, and smaller eggs (25-27 $\mu \mathrm{m} \times 7-9 \mu \mathrm{m} v s .53-73 \mu \mathrm{m} \times 11-17 \mu \mathrm{m})$. Breizacanthus aznari differs from $B$. irenae by the shorter body length of females (5.2-8.4 $\mathrm{mm}$ vs. $16.7 \mathrm{~mm})$, the different 


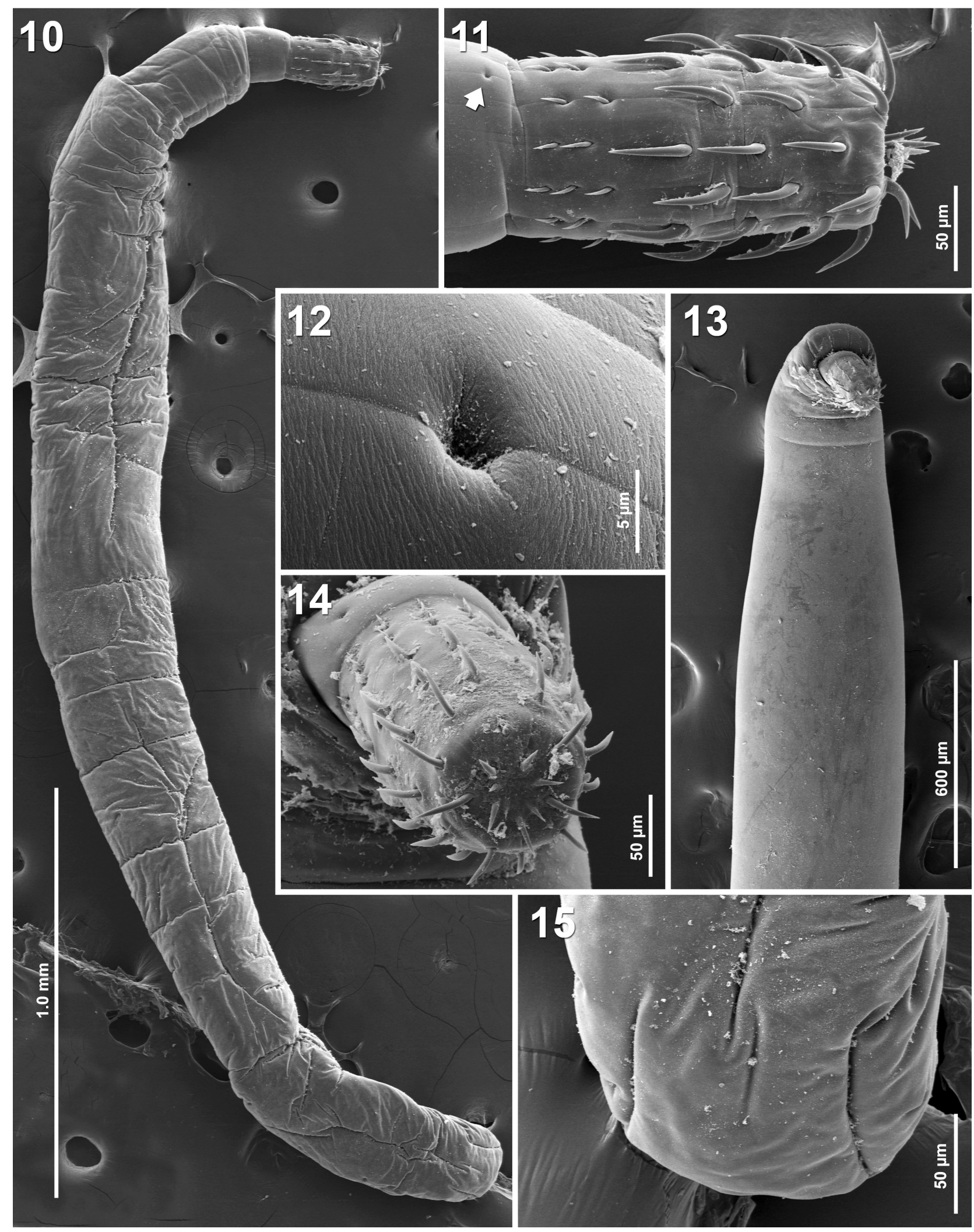

Figs. 10-15. Scanning electron micrographs of Breizacanthus aznari sp. n. from Raneya brasiliensis. 10. Male, whole worm, lateral view. 11. Male proboscis, lateral view showing longitudinal rows of 2-3 small basal hooks, 3-4 large subapical hooks and large apical hooks slightly invaginated. Arrow points to a sensory pit. 12. Male, detail of a sensory pit of the neck. 13. Female, anterior region of the body, ventral view. 14. Female proboscis, subapical view, distal large subapical hooks and apical large hooks invaginated. 15. Male, posterior body end, lateral view. 
Hernández-Orts et al.: Breizacanthus aznari sp. n.

Table 2. Biometrical data of males and females of species Breizacanthus. Measurements in micrometres, unless otherwise indicated.

\begin{tabular}{|c|c|c|c|c|c|}
\hline Species & B. chabaudi & B. irenae & B. ligur & B. golvani & B. aznari sp. $\mathrm{n}$. \\
\hline Reference & Golvan 1969 & Golvan 1969 & Paggi et al. 1975 & $\begin{array}{l}\text { Gaevskaya and } \\
\text { Shukhgalter } 1984\end{array}$ & Present study \\
\hline Hosts & Mullus surmuletus & M. surmuletus & $\begin{array}{l}\text { Argentina sphyraena, Chlorophthalmus } \\
\text { agassizi**, Gadiculus argenteus, Phycis } \\
\text { blennoides, Coelorinchus caelorhincus, } \\
\text { Capros aper, Synchiropus phaeton, } \\
\text { Helicolenus dactylopterus }\end{array}$ & Argentina sphyraena & Raneya brasiliensis \\
\hline Locality & Bay of Biscay & Algerian coast & Ligurian Sea & Bay of Biscay & Argentine coast \\
\hline \multicolumn{6}{|l|}{ Female } \\
\hline Body length (mm) & $15.0-20.0$ & 16.7 & $10.3-24.7$ & $4.5-13.4$ & $5.2-8.4$ \\
\hline Proboscis & $430 \times 180$ & $400 \times 140$ & $250-380 \times 130-170$ & $380-580 \times 110-140$ & $272-375 \times 96-184$ \\
\hline $\begin{array}{l}\text { No. longitudinal rows of } \\
\text { hooks }\end{array}$ & $16-18$ & 12 & 12 & 12 & 12 \\
\hline No. large hooks per row & $6-7$ & $5-6$ & $5-6$ & $8-9$ & 5 \\
\hline No. small hooks per row & $3-4$ & $3-4$ & $2-3$ & $2-3$ & $2-3$ \\
\hline Proboscis receptacle & $1100 \times 130$ & $1020 \times 150$ & $600-830 \times 150-200$ & $440-480$ & $414-724 \times 78-129$ \\
\hline Lemniscus length & $2115-2187 *$ & $1875-2062 *$ & $780-1340$ & $520-900$ & $466-905$ \\
\hline Egg size & $60-22$ & $55 \times 11$ & $50-60 \times 18-21$ & $25-27 \times 7-9$ & $53-73 \times 11-17$ \\
\hline \multicolumn{6}{|l|}{ Male } \\
\hline Body length (mm) & $9-11$ & 6.2 & $5.8-11.5$ & $3.1-5.6$ & $4.7-6.0$ \\
\hline Proboscis & $430 \times 180$ & $400 \times 140$ & $200-350 \times 120-180$ & $240-370 \times 90-120$ & $288-560 \times 124-259$ \\
\hline $\begin{array}{l}\text { No. longitudinal rows of } \\
\text { hooks }\end{array}$ & $16-18$ & 12 & 12 & 12 & 12 \\
\hline No. large hooks per row & $6-7$ & 6 & $5-6$ & $8-9$ & $4-5$ \\
\hline No. small hooks per row & $3-4$ & 3 & $2-3$ & $2-3$ & $2-3$ \\
\hline Proboscis receptacle & $900 \times 130$ & $550 \times 90$ & $630-810 \times 100-160$ & $220-480 \times 80-110$ & $466-586 \times 95-134$ \\
\hline Lemniscus length & $1762-2408 *$ & $1123 *$ & $830-1130$ & $440-840$ & $534-691$ \\
\hline Testis size & $1050-1250 \times 250$ & $\begin{array}{l}620-800 \times \\
200-220\end{array}$ & $500-1050 \times 300-520$ & $260-660 \times 120-280$ & $368-926 \times 168-432$ \\
\hline
\end{tabular}

*Calculated from figures. ** Since type host was not explicitly designated in the original description by Paggi et al. 1975, Chlorophthalmus agassizi is considered to be type host because acanthocephalans from this host were used for the original description of $B$. lingur.

range of numbers of large hooks per row of males (4-5 and 5-6, respectively), the smaller maximum number of small hooks per row of females (3 and 4, respectively), and shorter lemnisci (466-905 $\mu \mathrm{m}$ vs. 1.9-2.1 $\mathrm{mm}$ in females and 534-691 $\mu \mathrm{m} v s .1 .1 \mathrm{~mm}$ in males). The new species is distinguishable from $B$. ligur by the shorter body length of females (5.2-8.4 $\mathrm{mm} v s .10 .3-24.7 \mathrm{~mm})$, the shorter maximum body length of males $(6.0 \mathrm{~mm} \mathrm{vs}$. $11.5 \mathrm{~mm})$, the different range of numbers of large hooks in each row of males (4-5 and 5-6, respectively), and shorter lemnisci (534-691 $\mu \mathrm{m}$ vs. 830-1 $130 \mu \mathrm{m})$.

Breizacanthus aznari is the only known species of the genus infecting the intestine of a fish of the order Ophidiiformes. The other species have been recorded from the intestine of fishes of the orders Aulopiformes (Chlorophthalmidae), Gadiformes (Gadidae, Macrouridae, Phycidae), Osmeriformes (Argentinidae), Perciformes (Callionymidae, Caproidae, Mullidae), and Scorpaeniformes (Sebastidae). Finally, the new species is the first species in this genus found in the Southern Hemisphere (along the southwestern Atlantic coast of Argentina). The other species have been reported from the Northern Hemisphere: B. chabaudi and B. golvani were found in the northeastern Atlantic (both species from the Bay of Biscay), whereas $B$. irenae and B. ligur were described from the Mediterranean Sea (Algerian coast and Ligurian Sea, respectively).

\section{DISCUSSION}

According to the revision of the family Arhythmacanthidae by Pichelin and Cribb (1999), only three genera have a trunk completely devoid of spines, namely Breizacanthus, Euzetacanthus Golvan et Houlin, 1964, and Paracanthocephaloides Golvan, 1969. In the key to the arhythmacanthid genera provided by these authors, $\mathrm{Pa}$ racanthocephaloides differs from the two other genera by the globular or claviform shape of the proboscis, whereas the proboscis is cylindrical in Euzetacanthus and Breizacanthus. Pichelin and Cribb (1999) distinguished Euzetacanthus from Breizacanthus by the shorter lemnisci compared to the proboscis receptacle and by the dilatations of the anterior and posterior end of the trunk, whereas the lemnisci are longer than the receptacle in Breizacanthus, and only the anterior end of the trunk is dilated. Nevertheless, we have observed some inconsistencies in these morphological characters in some species of both genera, according to their descriptions: (i) the lemnisci are slightly larger than the receptacle in Euzetacanthus simplex Golvan et Houin, 1964 (see Figs. 132 and 133 in Golvan 1969); (ii) in E. chorinemusi Gupta et Naqvi, 1984 and in E. golvani Gupta et Fatma, 1983, only the anterior body end is dilated (Gupta and Naqvi 1982, Gupta and Fatma 1983); and (iii) in B. golvani only the posterior body end is dilated (Gaevskaya and Shukhgalter 1984). 
Table 3. Comparison of selected morphological data between Euzetacanthus and Breizacanthus obtained from the descriptions (or figures) of all species in both genera.

\begin{tabular}{|c|c|c|}
\hline & Euzetacanthus Golvan et Houlin, 1964 & Breizacanthus Golvan, 1969 \\
\hline References & $\begin{array}{l}\text { Golvan (1969), Gupta and Naqvi (1982), } \\
\text { Gupta and Fatma (1983) }\end{array}$ & $\begin{array}{l}\text { Golvan (1969), Paggi et al. (1975), Gaevskaya and Shukhgalter } \\
\text { (1984); present study }\end{array}$ \\
\hline Species & $\begin{array}{l}\text { E. chorinemusi, E. golvani* and } \\
\text { E. simplex }\end{array}$ & B. aznari sp. n., B. chabaudi, B. golvani, B. irenae and B. ligur \\
\hline Host Family & Ariidae, Carangidae and Mullidae & $\begin{array}{l}\text { Argentinidae, Callionymidae Caproidae, Chlorophthalmidae, } \\
\text { Gadidae, Macrouridae, Mulidae, Ophidiidae, Phycidae and } \\
\text { Sebastidae }\end{array}$ \\
\hline Locality & $\begin{array}{l}\text { Denmark coast, Indian Ocean, western } \\
\text { Mediterranean }\end{array}$ & $\begin{array}{l}\text { northeastern Atlantic, southwestern Atlantic, western Mediter- } \\
\text { ranean }\end{array}$ \\
\hline \multicolumn{3}{|r|}{ 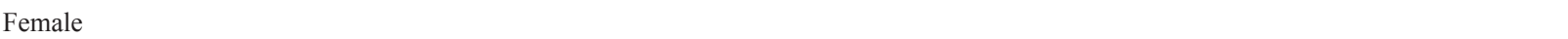 } \\
\hline Body length (mm) & $7.0-26.0$ & $5.2-24.7$ \\
\hline No. longitudinal rows of hooks & 14 & $12,16-18$ \\
\hline No. large hooks per row & $6-8$ & $5-9$ \\
\hline No. small hooks per row & $2-3$ & $2-4$ \\
\hline $\begin{array}{l}\text { Proboscis receptacle / lemnisci } \\
\text { length ratio }\end{array}$ & $1: 0.9-1.1$ & $1: 0.5-0.8$ \\
\hline \multicolumn{3}{|l|}{ Male } \\
\hline Body length (mm) & $6.4-16.0$ & $3.2-11.5$ \\
\hline No. longitudinal rows of hooks & 14 & $12,16-18$ \\
\hline No. large hooks per row & $5-8$ & $4-9$ \\
\hline No. small hooks per row & $2-3$ & $2-4$ \\
\hline $\begin{array}{l}\text { Proboscis receptacle / lemnisci } \\
\text { length ratio }\end{array}$ & $1: 1.0-1.2$ & $1: 0.4-0.8$ \\
\hline
\end{tabular}

* Measurements from a single male specimen.

In Table 3, we present a comparison of biometrical data between Euzetacanthus and Breizacanthus based on the description of all species of each genus. In view of these data, we agree with Pichelin and Cribb (1999) in their advice that there are few morphological characters to separate both genera. Further study, based on molecular analyses and/or detailed morphological descriptions of type and new specimens of the species of Euzetacanthus and Breizacanthus must be performed to properly explore the validity of these genera. However, accepting the current taxonomy, we suggest that the extension of the lemnisci compared to the proboscis receptacle seems to be the most useful morphological character to distinguish both genera: lemnisci are shorter, equal or slightly longer than the receptacle in Euzetacanthus, whereas the lemnisci are always clearly longer in Breizacanthus (see Table 3).

To our knowledge, B. aznari is the fifth species of arhythmacanthid reported along the southwestern Atlantic coast of Argentina. The four other species recorded are: (i) Heterosentis heteracanthus (Linstow, 1896) from the nototheniids Patagonotothen longipes (Steindachner) and $P$. tessellata (Richardson) and from the channichthyid Champsocephalus esox (Günther) in the eastern mouth of the Beagle Channel (Laskowski and Zdzitowiecki 2009); (ii) Heterosentis martini Lanfranchi et Timi, 2011 from the pinguipedids Pseudopercis semifasciata (Cuvier) and Pinguipes brasilianus (Cuvier) from the coast of Mira- mar, Necochea, Villa Gesell, and offshore of Península Valdés (Lanfranchi and Timi 2011); (iii) Hypoechinorhynchus magellanicus Szidat, 1950 from the eleginopidid Eleginops maclovinus (Cuvier, 1830) and from the channichthyid C. esox in Tierra del Fuego and the eastern mouth of the Beagle Channel (Szidat 1950, Laskowski and Zdzitowiecki 2009); and (iv) Hypoechinorhynchus sp. from the atherinopsidids Odontesthes smitti (Lahille) and Odontesthes nigricans (Richardson), in the Patagonian coast (Carballo et al. 2011).

Acknowledgements. We are indebted to R. Míguez-Lozano, A. Juan-García, N. Vera, M. Ferrer-Montell, S. Leonardi and V. Barraza for their technical assistance. Thanks are also given to Prefectura Naval Argentina and ALPESCA S.A. for allowing us to collect our material on the hake trawlers. This study was supported by the following projects: BBVA project $n$. BIOCON 04, AGL2010-20892 from the Spanish Government, PROMETEO 2011-040 of the Valencian Government and the Czech Science Foundation (No. P505/12/G112). J.S.H.O. received a $\mathrm{PhD}$ student grant from the National Council on Science and Technology (CONACyT) of the Mexican Government for the $\mathrm{PhD}$ program in Biodiversity and Evolutionary Biology of the Cavanilles Institute of Biodiversity and Evolutionary Biology, of the University of Valencia (scholarship number 197266). Institutional support was given by the Centro Nacional Patagónico (CONICET, Argentina) and the Institute of Parasitology (RVO:60077344). 


\section{REFERENCES}

Bush A.O., Lafferty K.D., Lotz J.M., Shostak A.W. 1997: Parasitology meets ecology on its own terms: Margolis et al. revisited. J. Parasitol. 83: 575-583.

Carballo M.C., Navone G.T., Cremonte F. 2011: Parasites of the silversides Odontesthes smitti and Odontesthes nigricans (Pisces: Atherinopsidae) from Argentinean Patagonia. Comp. Parasitol. 78: 95-103.

Gaevskaya A.V., Shukhgalter O.A. 1984: [Species composition, ecological-geographical peculiarities and formation of the acanthocephalan fauna of the North-East Atlantic.] Biol. Morya 3: 349-375. (In Russian.)

Golvan Y.J. 1969: Systematique des acanthocéphales (Acanthocephala Rudolphi, 1801). L'ordre des Palaeacanthocephala Meyer 1931. I. La super-famille des Echinorhynchoidea (Cobbold, 1876) Golvan et Houin 1963. Mem. Mus. Natl. Hist. Nat. 57: 1-373.

Gupta V., Fatma S. 1983: On some acanthocephalan parasites of fishes. Ind. J. Helminthol. 35: 137-154.

Gupta V., Naqvi M. 1982: On some acanthocephalan parasites of marine fishes from India and Pakistan. Ind. J. Helminthol. 34: 61-84.

Lanfranchi A.L., Timi J.T. 2011: A new species of Heterosentis Van Cleave, 1931 (Acanthocephala, Arhythmacanthidae),

Received 27 April 2012 a parasite of pinguipedid fishes in the southwest Atlantic. J. Parasitol. 97: 111-115.

LAskowski Z., ZDZitowiecki K. 2009: Occurrence of acanthocephalans in notothenioid fishes in the Beagle Channel (Magellanic sub-region, sub-Antarctic). Pol. Polar Res. 30: 179-186.

Muñoz G., George-Nascimento M. 2002: Spiracanthus bovichthys n. gen. n. sp. (Acanthocephala: Arhythmacanthidae), a parasite of littoral fishes of the central south coast of Chile. J. Parasitol. 88: 141-145.

Paggi L., Orecchia P., Della Seta G. 1975: Su di un nuovo acantocefalo Breizacanthus ligur sp. n. (Palaeacanthocephala: Arhythmacanthidae Yamaguti, 1935) parassita di alcune specie di pesci bentonici del Mar Ligure. Parassitologia 17: 8-94.

Pichelin S., CribB H. 1999: A review of the Arhythmacanthidae (Acanthocephala) with a description of Heterosentis hirsutus $\mathrm{n}$. sp. from Cnidoglanis macrocephala (Plotosidae) in Australia. Parasite 6: 293-302.

Szidat L. 1950: Los parásitos del róbalo ("Eleginops maclovinus" Cuv. \& Val.). Primer Congreso Nacional de Pesquería Marítimas e Industrias Derivadas. Mar del Plata, Buenos Aires, October 1949, 2: 235-270.

Accepted 29 August 2012 